\title{
Reducing lung function decline in patients with idiopathic pulmonary fibrosis: potential of nintedanib
}

This article was published in the following Dove Press journal:

Drug Design, Development and Therapy

18 June 2013

Number of times this article has been viewed

\author{
Hannah V Woodcock ${ }^{1,2}$ \\ Philip L Molyneaux ${ }^{1,3}$ \\ Toby M Maher ${ }^{1-3}$ \\ 'Interstitial Lung Disease Unit, Royal \\ Brompton Hospital, ${ }^{2}$ Centre for \\ Respiratory Research, University \\ College London, ${ }^{3}$ National Heart \\ and Lung Institute, Imperial College \\ London, London, UK
}

\begin{abstract}
Idiopathic pulmonary fibrosis (IPF) is a chronic, progressive, fibrotic lung disease with no clear etiology and a paucity of therapeutic options. Nintedanib (previously known as BIBF 1120) is a tyrosine kinase receptor antagonist which inhibits a number of key receptors, including those for platelet derived growth factor (PDGF), vascular endothelial growth factor (VEGF), and fibroblast growth factor (FGF). These growth factors are profibrotic and each has been investigated as a potential standalone therapeutic target in IPF. Simultaneous inhibition of these receptors, with an analog of nintedanib, has proved to be effective in experimental animal models of pulmonary fibrosis. This observation, together with extensive safety and pharmacokinetic data from studies of nintedanib in malignancy, paved the way for the clinical development of this drug in IPF. The Phase IIb TOMORROW trial demonstrated that treatment with nintedanib may potentially slow decline in lung function, decrease the frequency of acute exacerbations, and improve quality of life in patients with IPF. While these observations are drawn from a single clinical trial, taken together with the preclinical data they suggest that nintedanib may yet become an important therapeutic option for individuals with IPF. The results of ongoing parallel, international, multicenter Phase III clinical trials are therefore eagerly awaited.
\end{abstract}

Keywords: interstitial lung disease, BIBF 1120, clinical trials, usual interstitial pneumonia, acute exacerbation

\section{Introduction}

Idiopathic pulmonary fibrosis (IPF) is a chronic, progressive, fibrotic lung disease which has no clear etiology. ${ }^{1}$ It is the most common of all the idiopathic interstitial pneumonias, affecting seven to 16 people per 100,000 each year, and its incidence is rising. ${ }^{2-5}$ Lack of a proven effective therapy means prognosis is poor, with a median survival of 3 years post diagnosis. ${ }^{6}$

The mechanisms underlying the development and progression of IPF remain poorly understood, but current theories propose that the condition develops as a result of an aberrant wound healing response to repeated alveolar injury in genetically susceptible individuals. ${ }^{1}$ The consequence of this response is uncontrolled myofibroblast proliferation and differentiation, and abnormal extracellular matrix deposition, with excess collagen accumulation in the interstitium. Normal lung architecture is destroyed and replaced by scar tissue, which compromises lung function, resulting in progressive respiratory failure. The process of fibrosis is driven by myriad growth factors and their downstream intra-cellular signaling pathways. It is therefore unsurprising that multiple cell signaling pathways have been identified as potential therapeutic targets in IPF. ${ }^{7,8}$
Correspondence: Toby M Maher Interstitial Lung Disease Unit, Royal Brompton Hospital, Sydney Street, London, SW3 6NP, UK

Tel +44 20735 I 80I8

Fax +44 2073518951

Email t.maher@rbht.nhs.uk 
Despite these preclinical observations, pirfenidone, which was approved in Japan in 2008 and Europe in 2011, is the only licensed treatment currently available for individuals with IPF. ${ }^{9}$

Nintedanib, formally known by the development code BIBF 1120 , is an orally available 6-methoxycarbonylsubstituted indolinone (indolinones are either of two isomeric ketones derived from indoline, which itself is a bicyclic secondary amine consisting of fused benzene and pyrrolidine rings), ${ }^{10}$ which acts as a multiple-receptor tyrosine kinase inhibitor, and has recently shown promising results in a Phase II trial in IPF. ${ }^{11}$ Originally developed as a cancer treatment, nintedanib acts by simultaneously inhibiting three receptor families implicated in angiogenesis: platelet derived growth factor (PDGF); vascular endothelial growth factor (VEGF); and fibroblast growth factor (FGF). ${ }^{10}$ Single angiogenic inhibitors, such as those antagonizing VEGF receptors, have historically had limited success in clinical practice, due to redundancy in angiogenic pathways provided by a variety of proangiogenic growth factors including FGF and PDGF. Multiple-target receptor tyrosine kinase inhibitors, including nintedanib, have been developed to address this problem. ${ }^{12}$ Nintedanib has entered clinical trials for numerous malignancies, where it targets the neovascularization critical for tumor growth and metastasis. ${ }^{12-18}$ Phase III trials are ongoing in non-small-cell lung (LUME-Lung 1 and 2; NCT00805194, and NCT 00806819 respectively) and ovarian cancer (LUME-Ovar1; NCT01015118).

Importantly, PDGF, VEGF, and FGF are also critical profibrotic mediators which have been shown to play a role in driving the development of fibrosis. ${ }^{19}$ Encouraging results using nintedanib or its analog BIBF 1000 in vitro and in animal models of experimentally induced fibrosis, have paved the way for clinical development of the compound in IPF. ${ }^{19}$ The recent publication of a large Phase IIb study ${ }^{11}$ in IPF and the anticipated completion of two concurrent Phase III trials has raised the hope that nintedanib may prove to be an effective therapy for IPF. This review therefore aims to provide a synopsis of the current state of knowledge regarding the pharmacodynamics, pharmacokinetics (PK), therapeutic efficacy, and toxicity of nintedanib, based on the published literature.

\section{Preclinical validation}

Nintedanib is a potent, oral, small, molecule, intracellular inhibitor of the receptor tyrosine kinases PDGF receptor (R) $-\alpha$ and $-\beta$ (IC50 59 and $65 \mathrm{nmol} / \mathrm{L}$ ), VEGFR-1, -2, and, -3 (IC50 s 13-34 nmol/L) and FGFR-1, -2, and -3
(IC50s 37-108 nmol/L). ${ }^{10}$ Profiling of the human kinome demonstrates that nintedanib also inhibits a narrow range of other targets at pharmacologically relevant doses eg, Src family and Flt-3 kinases. Nintedanib competitively binds the ATP pocket binding site of its target receptor tyrosine kinase, resulting in interference of receptor dimerization and autophosphorylation of the tyrosine kinase domains, and inhibition of downstream signaling. ${ }^{12}$ The exact receptorbinding kinetics are not completely understood, however, it has been shown that nintedanib causes sustained ( $>32$ hours) inhibition of VEGFR-2 phosphorylation in pulse-chase experiments of VEGFR-2-transfected NIH3T3 cells. ${ }^{10}$

In preclinical oncology experiments with human tumor xenografts, nintedanib is effective in reducing tumor growth through inhibition of angiogenesis..$^{20}$ At present only limited data have been published on the effect of BIBF on fibrogenesis either in vitro or in vivo in animal models. The main published work assessing tyrosine kinase receptor inhibition in fibrosis utilized an analog of nintedanib, BIBF 1000. ${ }^{19}$ Chaudhary et al $^{19}$ demonstrated that $50 \mathrm{mg}$ per $\mathrm{kg}$ BIBF 1000, when dosed both prophylactically and therapeutically, inhibits the development of fibrosis in the rat bleomycin model (measured at day 22 by Masson's trichrome and procollagen 1 gene expression). The authors were also able to show that in in vitro experiments BIBF 1000, but not imatinib mesylate, blocks TGF- $\beta$-induced fibroblast to myofibroblast transformation, via SMAD independent pathways. Although TGF- $\beta$ acts as a potent profibrotic mediator, at physiological levels it is important in tissue homeostasis and acts as a modulator of inflammation and cell proliferation. The ability of BIBF 1000 to inhibit myofibroblast differentiation without affecting the canonical SMAD signaling pathway is potentially advantageous, particularly because studies in knockout mouse models suggest that global inhibition of TGF- $\beta$ as a strategy to treat fibrosis could have adverse side effects, such as inducing widespread inflammation and increasing the risk of malignancy. ${ }^{21}$

Although there is a paucity of pre-clinical data supporting the antifibrotic potential of nintedanib, an antifibrotic effect can be predicted from the compound's capacity to inhibit PDGF, FGF, and VEGF. PDGF comprises a family of dimers of two polypeptide chains, A and B. These dimers interact with PDGF- $\alpha$ or $-\beta$ tyrosine kinase receptors, resulting in activation of downstream Pi3K and MAPK pathways. PDGF-A and PDGF-B are potent fibroblast mitogens and chemotractants. In addition, in vitro, PDGF is important in mediating TGF- $\beta$, IL-1, TNF $\alpha$, FGF, and thrombin fibrotic responses. ${ }^{22-26}$ In rat lung, administration of an adenoviral 
vector containing PDGF-B results in a mild fibroproliferative response. ${ }^{27}$ Furthermore, PDGFR selective tyrosine kinase inhibitors have been shown to reduce pulmonary fibrosis in a rat model of vanadium pentoxide induced lung injury ${ }^{28}$ and a murine model of radiation induced fibrosis. ${ }^{29}$ PDGF is synthesized by alveolar macrophages. ${ }^{23}$ Macrophages extracted from bronchoalveolar lavage fluid from patients with IPF produce four times the amount of PDGF compared to macrophages from normal lungs. ${ }^{30}$ In IPF, hyperplastic type II pneumonocytes strongly express messenger ribonucleic acid (mRNA) for PDGF-B and for PDGF receptors. ${ }^{31}$ Fibroblasts derived from IPF also produce PDGF. ${ }^{31}$ Imantinib mesylate, a PDGFR and cAbl inhibitor, reduces murine bleomycin-mediated lung fibrosis when administered prophylactically. ${ }^{32}$ However, in a Phase IIb clinical trial, while imantinib-treated subjects showed significant improvement in oxygenation at 48 weeks, there were no significant differences in the primary endpoints of survival or improvement in lung function compared to placebo. ${ }^{33}$ While these data might argue against the efficacy of PDGF targeted therapy, rodent studies have suggested that one of the mechanisms of action of the novel antifibrotic agent pirfenidone is inhibition of PDGF synthesis. ${ }^{34}$

The FGFs are a family of pluripotent growth factors which act on many different cells types via high affinity FGFRs including FGFR-1 and -2. Basic (b) FGF (also known as FGF-2) potently induces the proliferation of many cell types involved in wound healing, including fibroblasts, endothelial cells, and smooth muscle cells. High levels of bFGF have been found in bronchoalveolar lavage and serum of patients with IPF. ${ }^{35,36}$ Production of bFGF by type II pneumonocytes is stimulated by TGF- $\beta .^{37,38}$ In vitro, FGFR-1 inhibitors reduce murine fibroblast proliferation and in a murine bleomycin model of fibrosis, administration of a soluble mutant FGF receptor with high binding affinity for bFGF attenuated fibrosis. ${ }^{39}$

VEGF is a critical mediator of angiogenesis which drives endothelial cell proliferation and vessel formation predominantly through VEGFR-2. ${ }^{40}$ Interestingly, in a rat model of adenoviral TGF- $\beta$ overexpression-induced pulmonary fibrosis, VEGF increases microvessel density and attenuates the development of pulmonary hypertension but at the cost of exaggerated fibrosis. ${ }^{41}$ Angiogenesis is important in the normal wound healing response. Aberrant neovascularization is a recognized histological feature in IPF tissue, with marked regional heterogeneity in vascular density. ${ }^{42}$ In general, vascularity is increased in areas bounding fibrosis while fibroblastic foci are hypovascular.
Although the exact role of angiogenesis in the fibrotic process is still debated, increased angiogenic activity secondary to an imbalance in angiogenic and angiostatic factors is seen in human fibrotic lung tissue. ${ }^{43}$ PDGF and FGF act synergistically to induce endothelial cell proliferation, and contribute to pericyte recruitment and stability of blood vessel walls. ${ }^{44}$ Early administration of a VEGFR-2 inhibitor or a soluble VEGF-1 decoy receptor in the murine bleomycin model attenuates fibrosis, microvessel formation, and bronchoalveolar lavage inflammatory cell counts. ${ }^{45}$ In vitro, nintedanib inhibits VEGF-, PDGF-, and FGFmediated proliferation of the three cell types contributing to angiogenesis: endothelial cells; vascular smooth muscle cells; and pericytes (EC50 10-79 nmol/L). In vivo, nintedanib reduces tumor microvessel density. ${ }^{12}$

\section{Pharmacokinetics}

Extensive data on the PK of nintedanib have been derived from trials in subjects with malignancy. Several Phase I studies have examined the safety and pharmacokinetic parameters of nintedanib as a monotherapy ${ }^{46}$ or in combination with other chemotherapeutic agents. ${ }^{14-16}$ In a 4-week Phase I accelerated dose titration study of nintedanib monotherapy in 61 individuals with advanced solid malignancies, subjects were treated with escalating doses of oral nintedanib, to a maximum dose of $450 \mathrm{mg}$ once daily or $300 \mathrm{mg}$ twice daily. PK profiles were measured at a steady state. Absorption of oral nintedanib was relatively fast, with maximum concentration $\left(\mathrm{C}_{\max }\right)$ reached at 1-3 hours following twice-daily dosing. The $\mathrm{C}_{\max }$ and exposure, as measured by the area under the curve, increased with increasing doses of nintedanib. The volume of distribution ranged from 10.1-25.4 L depending on the dose, suggesting a high tissue distribution. It should be noted however, that the bioavailability of nintedanib was not calculated. In this study, a terminal half-life $\left(t_{1 / 2}\right)$ of 12.9-19 hours was observed. There was, however, significant variability in the PK parameters between subjects which the authors attributed to the mixed nature of the study cohort. The maximum tolerated dose was $250 \mathrm{mg}$. Twice daily administration of this dose was better tolerated, with greater drug exposure, than higher doses given once daily.

Okamoto et al conducted a similar Phase I trial of nintedanib in Japanese patients with advanced solid malignancy. ${ }^{47}$ The maximum tolerated dose in this cohort was $200 \mathrm{mg}$ twice daily. Multiple dosing PK measurements were in keeping with data from other studies ${ }^{17,46}$ with fast absorption, $\mathrm{C}_{\max }$ at 2-3 hours and a terminal $t_{1 / 2}$ of 19-23 h. In a study of eight healthy white male volunteers (mean age 32.3 years), the 
PK and metabolism of a single dose of $\left[{ }^{14} \mathrm{C}\right]$-radiolabeled nintedanib was analyzed. Following fasted administration of an oral solution of $100 \mathrm{mg}$, nintedanib was detected in plasma at 15 minutes, with $\mathrm{C}_{\max }$ achieved at 1.3 hours. ${ }^{48}$ Mean $t_{1 / 2}$ was 13.7 hours and the area under the curve was $61.3 \mathrm{ng} \cdot \mathrm{h} / \mathrm{mL}$.

In vitro, nintedanib is rapidly metabolized by hepatocytes via ester cleavage to form the metabolite BIBF 1202. Extensive metabolite pattern analysis undertaken on the plasma, urine, and feces of healthy human volunteers after administration of $\left[{ }^{14} \mathrm{C}\right]$-radiolabeled nintedanib revealed $\mathrm{BIBF}$ 1202 and its glucuronic acid conjugate, 1-0 acylglucorinde as the most prevalent metabolites. ${ }^{48}$ In healthy volunteers, BIBF 1202 was detected along with the parent compound 15 minutes after nintedanib administration with $\mathrm{C}_{\max }$ for BIBF 1202 being reached at 2.5 hours. The authors speculate that the rapid appearance of the metabolite results from first pass metabolism in the intestinal wall. The major route of metabolite elimination is via the liver and through excretion in feces. There is minimal excretion in the urine.

The hepatic metabolism of nintedanib is mainly CYP450 independent. ${ }^{49}$ Consequently, there is a lack of inhibition of CYP450 enzymes (inhibitory concentration $[\mathrm{IC}] 50>50 \mu \mathrm{M})$ by nintedanib, BIBF 1202, and 1-0 acylglucuronide and there have been no reported drugdrug interactions from clinical trials in malignancy. A trial examining the effect of ketoconazole on the pharmacokinetics of nintedanib in healthy volunteers is currently underway (ClinicalTrials.gov identifier: NCT01679613). There are no published PK studies in patients with IPF.

\section{Clinical trials of nintedanib in IPF}

With the safety of nintedanib having been established in oncology studies, and animal data suggesting an antifibrotic role for the compound, it was logical that the drug be trialled in patients with IPF. The TOMORROW (To imprOve pulMOnaRy fibROsis With BIBF1120) study, a 12-month double blinded, randomized, dose-ranging placebo-controlled Phase II trial investigating the efficacy and safety of nintedanib in IPF, reported in 2011. ${ }^{11}$ Richeldi et al randomized 432 subjects to receive one of four nintedanib dosing regimens (50 mg once daily, $50 \mathrm{mg}$ twice daily, $100 \mathrm{mg}$ twice daily, or $150 \mathrm{mg}$ twice daily) or placebo. An increasing dose strategy was initially employed, with safety data reviewed by an independent committee before each dose escalation. The primary endpoint for the study was the annual rate of forced vital capacity (FVC) decline. Secondary endpoints measured included absolute change in FVC, total lung capacity, total lung diffusion capacity for carbon monoxide (DLCO), 6-minute walk distance, acute exacerbation rate, quality of life (measured with the St George's Respiratory Questionnaire [SGRQ]), and survival.

At the time of enrollment, patients had, on average, mild to moderate IPF with a mean FVC of $81.3 \%$ predicted, a mean DLCO of $3.8 \mathrm{mmol} / \mathrm{minute} / \mathrm{kPa}$, and median resting oxygen saturations of $96 \%$. In terms of diagnostic certainty, there were 141 (32.9\%) definite, 265 (61.9\%) probable, and $21(4.9 \%)$ possible cases of IPF (one individual was found not to have IPF). Of the 428 enrolled subjects 128 had been diagnosed with IPF following surgical lung biopsy. Study subjects were permitted concomitant therapy with up to $15 \mathrm{mg}$ daily of prednisolone. Use of either $\mathrm{N}$-acetyl cysteine or pirfenidone was an exclusion criteria and neither was permitted for the duration of the study.

A number of challenges face IPF clinical trial investigators. Firstly the choice of primary endpoint remains contentious. ${ }^{50-52}$ There is, however, an emerging consensus, backed by a growing body of data that change in FVC provides a reasonable surrogate for longer term prognosis and survival. ${ }^{51,53}$ Furthermore, a recent analysis by du Bois et al, ${ }^{51}$ using data from several published IPF clinical trials, has demonstrated that the minimal clinically important difference in FVC over 12 months lies between $2 \%$ and $6 \%$. The second challenge is that of handling missing data. While this is a problem in all clinical trials, it is one that tends to be magnified in IPF due to the length of the studies and the progressive nature of the disease (resulting in study subjects who die or become too unwell to undertake spirometry). Simplistic handling of missing data has hampered the interpretation of previous IPF clinical trials. ${ }^{54,55}$ In the TOMORROW study, the investigators calculated the change in FVC for every individual by modeling the linear decrease in FVC for each subject from the time of first dose until the last study observation undertaken for that subject. This modeling took into account all FVC readings performed by each subject during the study and ensured robust handling of missing data values. ${ }^{11}$

Because of the multiple dosing groups included in the study, analysis of the primary endpoint was with a closed hierarchical testing procedure, with correction for multiplicity. The multiplicity correction, added to avoid type I error, raised the threshold required for the study to achieve statistical significance. Using this approach the pre-defined primary endpoint did not differ significantly ( $P=0.06)$ between the group of subjects receiving the highest dose of nintedanib (150 mg twice daily) and the placebo. However, the annual rate of decline in the $150 \mathrm{mg}$ twice daily 
group was $0.06 \mathrm{~L}$ compared to $0.19 \mathrm{~L}$ in the placebo group. Hierarchical comparison of these groups (without correction for multiplicity) pointed towards a significant difference between groups $(P=0.01)$. Subsequent, post hoc, sensitivity analyses of the primary endpoint using a conservative, closed testing procedure adjusting for multiplicity, show significant differences between the placebo and the highest dose group with: (1) inclusion of baseline values and unscheduled visits ( $P=0.0058)$; (2) analysis by final dose $(P=0.0047)$; (3) use of data from week 6 only $(P=0.0202)$; and (4) inclusion of time as a fixed effect in the model $(P=0.0007){ }^{56}$

Despite the study's failure to achieve the primary endpoint, there were a number of clinically important and significant changes in prespecified secondary outcomes in the highest treatment dose arm compared to placebo. Fewer patients had a major $(>10 \%$ or $>200 \mathrm{~mL})$ decline in FVC (20 [23.8\%] versus 37 [44\%], $P<0.01$ ). The adjusted mean absolute change from baseline in total lung capacity $(+0.12 \mathrm{~L}$ versus $-0.24 \mathrm{~L}, P<0.001)$ and resting oxygen saturations $(-0.2 \%$ versus $-1.3 \%, P=0.02)$ were significantly different between the nintedanib $150 \mathrm{mg}$ twice daily group and placebo. SGRQ scores when compared to baseline showed an improved quality of life in the high dose nintedanib group, compared to worsening scores in the placebo group $(-0.66$ points versus +5.46 points, $P=0.007) .{ }^{57}$ The magnitude of difference between the two groups exceeds the minimum clinically significant difference in SGRQ of 5 points that has been reported for individuals with IPF. ${ }^{58}$

Perhaps one of the most striking results in the study was the reduction in acute exacerbations seen in patients receiving $150 \mathrm{mg}$ twice daily compared to placebo (2 [2.3\%] versus 12 [13.8\%] or 2.4 versus 15.7 per 100 patient years, $P=0.02)$. The reduction in exacerbation rate appeared to show a dose response effect across the four nintedanib dose groups. Acute exacerbations of IPF are characterized by rapid progression in symptoms and convey a 30-day risk of mortality approaching 50\%. ${ }^{59}$ Prevention of acute exacerbations is therefore an important treatment effect. Some caution must, however, be applied in interpreting this result. Firstly, acute exacerbations are frequently challenging to distinguish from other acute onset respiratory disease, such as infection. ${ }^{60}$ Secondly, early phase trials of other therapeutic agents in IPF have suggested important effects on rate of acute exacerbations which have not subsequently been borne out in larger Phase III studies. ${ }^{61,62}$ However, in support of the observed reduction in acute exacerbations in the TOMORROW study, a trend towards lower respiratoryrelated mortality was observed in both the $100 \mathrm{mg}$ and
$150 \mathrm{mg}$ twice daily treatment arms $(P=0.04$ and $P=0.06$, respectively).

The results of the TOMORROW study were sufficiently positive for Boehringer Ingelheim to undertake two parallel Phase III registration studies of nintedanib in IPF (NCT01335464 and NCT01335477). These studies, IMPULSIS I and II, are identical 52-week trials of nintedanib $150 \mathrm{mg}$ twice daily compared to placebo. As with the TOMORROW study the primary endpoint is annual rate of decline in FVC (expressed in $\mathrm{mL}$ over 52 weeks). Target recruitment was approximately 550 subjects for each study. Both trials were initiated in April 2011 and it is anticipated that the final study visit will be conducted in late 2013 . It is to be hoped therefore that results will be available in early 2014.

\section{Safety}

The safety of nintedanib has been assessed in a number of open label, dose escalation Phase I trials for the treatment of solid cancers where doses up to $500 \mathrm{mg}$ per day have been administered. ${ }^{14,16-18,46,47,63,64}$ Nintedanib has generally been well tolerated in these studies. The most frequently occurring reported adverse events have been nausea, diarrhea, and vomiting. While other anti-angiogenic treatments have been associated with hypertension, this has not been reported with nintedanib.

In line with data from studies in malignancy, the most frequent adverse events reported in the TOMORROW trial were diarrhea (27\%), nausea (14.5\%), and vomiting $(7.7 \%) .{ }^{11}$ Serious adverse events rates were similar between groups, although the discontinuation rate due to adverse events was highest in the $150 \mathrm{mg}$ twice daily group at $30.6 \%$. This rate is in comparison to $25.9 \%$ in the placebo group and $14.0 \%$ in the $100 \mathrm{mg}$ twice daily group. The majority of the reported diarrhea cases were mild or moderate. The rate of gastrointestinal side effects rose with increasing doses of nintedanib, with $8.2 \%$ of patients in the maximal dosing arm reporting serious or severe diarrhea compared to $1.2 \%$ and $0 \%$ in the $50 \mathrm{mg}$ twice daily and placebo arms, respectively. Only 12 subjects (across all arms) discontinued the drug due to diarrhea.

Elevation of liver enzymes occurred more frequently in subjects receiving $300 \mathrm{mg} /$ day of nintedanib when compared to placebo. There were, however, only nine clinically significant episodes of liver enzyme elevation (three times upper limit of normal range) across all of the treatment arms. Only two patients needed to discontinue the drug due to hepatotoxicity, and there were no cases of 
drug-induced liver failure. All liver function tests normalized with either reduction or discontinuation of nintedanib. Ongoing safety studies include an open label extension of the TOMORROW trial (NCT01170065) and a study, in Japanese subjects, of nintedanib given together with pirfenidone (NCT01417156).

\section{Conclusion}

IPF is a progressive and invariably fatal disease. Although the pathogenesis of the condition remains unknown, there is encouraging animal data to suggest that targeting PDGFR, VEGFR, and FGFR ameliorates the development of fibrosis. The multiple targeting of these three profibrotic mediators by the novel tyrosine kinase inhibitor, nintedanib, has led to promising Phase II clinical trial results. Data from the TOMORROW study suggest that high dose oral nintedanib is able to slow the decline of lung function and reduce the rate of acute exacerbations in individuals with mild and moderate IPF. Importantly for patients with this chronic progressive disease, nintedanib also improved quality of life, compared with the placebo. The results of two currently active, parallel, Phase 3, placebo-controlled trials of nintedanib are eagerly awaited. It is to be hoped that these studies will provide verification of the results of the TOMORROW study. Should they do so, nintedanib will become an important and very welcome addition to the therapeutic armamentarium of physicians treating patients with IPF.

\section{Disclosure}

Toby M Maher is in receipt of an unrestricted academic industry grant from GlaxoSmithKline. In the last 3 years, TMM has received advisory board or consultancy fees from Actelion, Boehringer Ingelheim, GlaxoSmithKline, InterMune, Respironics, and Sanofi-Aventis. TMM has received speaker's fees from UCB, Boehringer Ingelheim, and AstraZeneca. TMM's institution has received an unrestricted educational grant from InterMune. Philip L Molyneaux's institution has received reimbursement for his conference travel from Boehringer Ingelheim. Hannah V Woodcock has no conflicts of interest to declare.

\section{References}

1. Maher TM, Wells AU, Laurent GJ. Idiopathic pulmonary fibrosis: multiple causes and multiple mechanisms? Eur Respir Journal. 2007;30(5):835-839.

2. Navaratnam V, Fleming KM, West J, et al. The rising incidence of idiopathic pulmonary fibrosis in the UK. Thorax. 2011;66(6):462-467.

3. Gribbin J, Hubbard RB, Le JI, Smith CJ, West J, Tata LJ. Incidence and mortality of idiopathic pulmonary fibrosis and sarcoidosis in the UK. Thorax. 2006;61(11):980-985.
4. Raghu G, Weycker D, Edelsberg J, Bradford WZ, Oster G. Incidence and prevalence of idiopathic pulmonary fibrosis. Am J Respir Crit Care Med. 2006;174(7):810-816.

5. Navaratnam V, Fogarty A, Glendening R, McKeever T, Hubbard RB. The increasing secondary care burden of idiopathic pulmonary fibrosis: hospital admission trends in England from 1998 to 2010. Chest. Epub September 24, 2012.

6. Ley B, Collard HR, King TE Jr. Clinical course and prediction of survival in idiopathic pulmonary fibrosis. Am J Respir Crit Care Med. 2011;183(4):431-440.

7. Datta A, Scotton CJ, Chambers RC. Novel therapeutic approaches for pulmonary fibrosis. Br J Pharmacol. 2011;163(1):141-172.

8. King TE Jr, Pardo A, Selman M. Idiopathic pulmonary fibrosis. Lancet. 2011;378(9807):1949-1961.

9. Maher TM. Pirfenidone in idiopathic pulmonary fibrosis. Drugs Today (Barc). 2010;46(7):473-482.

10. Roth GJ, Heckel A, Colbatzky F, et al. Design, synthesis, and evaluation of indolinones as triple angiokinase inhibitors and the discovery of a highly specific 6-methoxycarbonyl-substituted indolinone (BIBF 1120). J Med Chem. 2009;52(14):4466-4480.

11. Richeldi L, Costabel U, Selman M, et al. Efficacy of a tyrosine kinase inhibitor in idiopathic pulmonary fibrosis. N Engl J Med. 2011;365(12): 1079-1087.

12. Hilberg F, Roth GJ, Krssak M, et al. BIBF 1120: triple angiokinase inhibitor with sustained receptor blockade and good antitumor efficacy. Cancer Res. 2008;68(12):4774-4782.

13. Santos ES, Gomez JE, Raez LE. Targeting angiogenesis from multiple pathways simultaneously: BIBF 1120, an investigational novel triple angiokinase inhibitor. Invest New Drugs. 2012;30(3):1261-1269.

14. Ellis PM, Kaiser R, Zhao Y, Stopfer P, Gyorffy S, Hanna N. Phase I open-label study of continuous treatment with BIBF 1120, a triple angiokinase inhibitor, and pemetrexed in pretreated non-small cell lung cancer patients. Clinical Cancer Res. 2010;16(10):2881-2889.

15. du Bois A, Huober J, Stopfer P, et al. A phase I open-label doseescalation study of oral BIBF 1120 combined with standard paclitaxel and carboplatin in patients with advanced gynecological malignancies. Ann Oncol. 2010;21(2):370-375.

16. Doebele RC, Conkling P, Traynor AM, et al. A phase I, open-label doseescalation study of continuous treatment with BIBF 1120 in combination with paclitaxel and carboplatin as first-line treatment in patients with advanced non-small-cell lung cancer. Ann Oncol. 2012;23(8): 2094-2102.

17. Kropff M, Kienast J, Bisping G, et al. An open-label dose-escalation study of BIBF 1120 in patients with relapsed or refractory multiple myeloma. Anticancer Res. 2009;29(10):4233-4238.

18. Ledermann JA, Hackshaw A, Kaye S, et al. Randomized phase II placebo-controlled trial of maintenance therapy using the oral triple angiokinase inhibitor BIBF 1120 after chemotherapy for relapsed ovarian cancer. J Clin Oncol. 2011;29(28):3798-3804.

19. Chaudhary NI, Roth GJ, Hilberg F, et al. Inhibition of PDGF, VEGF and FGF signalling attenuates fibrosis. Eur Respir J. 2007;29(5): 976-985.

20. Taeger J, Moser C, Hellerbrand C, et al. Targeting FGFR/PDGFR/ VEGFR impairs tumor growth, angiogenesis, and metastasis by effects on tumor cells, endothelial cells, and pericytes in pancreatic cancer. Mol Cancer Ther. 2011;10(11):2157-2167.

21. Akhurst RJ, Hata A. Targeting the TGFbeta signalling pathway in disease. Nat Rev Drug Discov. 2012;11(10):790-811.

22. Antoniades HN, Bravo MA, Avila RE, et al. Platelet-derived growth factor in idiopathic pulmonary fibrosis. J Clin Invest. 1990;86(4): $1055-1064$.

23. Bonner JC. Regulation of PDGF and its receptors in fibrotic diseases. Cytokine and Growth Factor Reviews. 2004;15(4):255-273.

24. Battegay EJ, Raines EW, Colbert T, Ross R. TNF-alpha stimulation of fibroblast proliferation. Dependence on platelet-derived growth factor (PDGF) secretion and alteration of PDGF receptor expression. Journal of immunology. 1995;154(11):6040-6047. 
25. Battegay EJ, Raines EW, Seifert RA, Bowen-Pope DF, Ross R. TGFbeta induces bimodal proliferation of connective tissue cells via complex control of an autocrine PDGF loop. Cell. 1990;63(3):515-524.

26. Kolb M, Margetts PJ, Anthony DC, Pitossi F, Gauldie J. Transient expression of IL-1beta induces acute lung injury and chronic repair leading to pulmonary fibrosis. J Clin Invest, 2001;107(12):1529-1536.

27. Yoshida M, Sakuma J, Hayashi S, et al. A histologically distinctive interstitial pneumonia induced by overexpression of the interleukin 6 , transforming growth factor beta 1, or platelet-derived growth factor B gene. Proc Nat Academy of Sciences of the United States of America. 1995;92(21):9570-9574.

28. Rice AB, Moomaw CR, Morgan DL, Bonner JC. Specific inhibitors of platelet-derived growth factor or epidermal growth factor receptor tyrosine kinase reduce pulmonary fibrosis in rats. Am Journal Pathol. 1999;155(1):213-221.

29. Abdollahi A, Li M, Ping G, et al. Inhibition of platelet-derived growth factor signaling attenuates pulmonary fibrosis. J Exp Med. 2005;201(6): 925-935.

30. Martinet Y, Rom WN, Grotendorst GR, Martin GR, Crystal RG. Exaggerated spontaneous release of platelet-derived growth factor by alveolar macrophages from patients with idiopathic pulmonary fibrosis. N Engl J Med. 1987;317(4):202-209.

31. Homma S, Nagaoka I, Abe H, et al. Localization of platelet-derived growth factor and insulin-like growth factor I in the fibrotic lung. Am J Respir Crit Care Med. 1995;152(6 Pt 1):2084-2089.

32. Daniels CE, Wilkes MC, Edens M, et al. Imatinib mesylate inhibits the profibrogenic activity of TGF-beta and prevents bleomycin-mediated lung fibrosis. J Clin Invest. 2004;114(9):1308-1316.

33. Daniels CE, Lasky JA, Limper AH, Mieras K, Gabor E, Schroeder DR. Imatinib treatment for idiopathic pulmonary fibrosis: randomized placebo-controlled trial results. Am J Respir Crit Care Med. 2010;181(6):604-610.

34. Gurujeyalakshmi G, Hollinger MA, Giri SN. Pirfenidone inhibits PDGF isoforms in bleomycin hamster model of lung fibrosis at the translational level. Am Journal Physiol. 1999;276(2 Pt 1):L311-L318.

35. Henke C, Fiegel V, Peterson M, et al. Identification and partial characterization of angiogenesis bioactivity in the lower respiratory tract after acute lung injury. J Clin Invest. 1991;88(4):1386-1395.

36. Inoue Y, King TE Jr, Barker E, Daniloff E, Newman LS. Basic fibroblast growth factor and its receptors in idiopathic pulmonary fibrosis and lymphangioleiomyomatosis. Am J Respir Crit Care Med. 2002;166(5):765-773.

37. Fan H, Duan Y, Zhou H, et al. Selection of peptide ligands binding to fibroblast growth factor receptor 1. IUBMB Life. 2002;54(2):67-72.

38. Calandrella N, Risuleo G, Scarsella G, et al. Reduction of cell proliferation induced by PD166866: an inhibitor of the basic fibroblast growth factor. J Exp Cin Cancer Res. 2007;26(3):405-409.

39. Yu ZH, Wang DD, Zhou ZY, He SL, Chen AA, Wang J. Mutant soluble ectodomain of fibroblast growth factor receptor-2 IIIc attenuates bleomycin-induced pulmonary fibrosis in mice. Biol Pharm Bull. 2012;35(5):731-736

40. Olsson AK, Dimberg A, Kreuger J, Claesson-Welsh L. VEGF receptor signalling - in control of vascular function. Nat Rev Mol Cell Biol. 2006;7(5):359-371.

41. Farkas L, Farkas D, Ask K, et al. VEGF ameliorates pulmonary hypertension through inhibition of endothelial apoptosis in experimental lung fibrosis in rats. J Clin Invest. 2009;119(5):1298-1311.

42. Renzoni EA, Walsh DA, Salmon M, et al. Interstitial vascularity in fibrosing alveolitis. Am J Respir Crit Care Med. 2003;167(3):438-443.

43. Keane MP, Arenberg DA, Lynch JP III, et al. The CXC chemokines, IL-8 and IP-10, regulate angiogenic activity in idiopathic pulmonary fibrosis. J Immunol. 1997;159(3):1437-1443.

44. Nissen LJ, Cao R, Hedlund EM, et al. Angiogenic factors FGF2 and PDGF-BB synergistically promote murine tumor neovascularization and metastasis. J Clin Invest. 2007;117(10):2766-2777.
45. Hamada N, Kuwano K, Yamada M, et al. Anti-vascular endothelial growth factor gene therapy attenuates lung injury and fibrosis in mice. J Immunol. 2005;175(2):1224-1231.

46. Mross K, Stefanic M, Gmehling D, et al. Phase I study of the angiogenesis inhibitor BIBF 1120 in patients with advanced solid tumors. Clin Cancer Res. 2010;16(1):311-319.

47. Okamoto I, Kaneda H, Satoh T, et al. Phase I safety, pharmacokinetic, and biomarker study of BIBF 1120 , an oral triple tyrosine kinase inhibitor in patients with advanced solid tumors. Mol Cancer Ther. 2010;9(10):2825-2833.

48. Stopfer P, Rathgen K, Bischoff D, et al. Pharmacokinetics and metabolism of BIBF 1120 after oral dosing to healthy male volunteers. Xenobiotica. 2011;41(4):297-311.

49. Gori B, Ricciardi S, Fulvi A, Intagliata S, Del Signore E, de Marinis F. New antiangiogenics in non-small cell lung cancer treatment: vargatef (BIBF 1120) and beyond. Ther Clin Risk Manag. 2011;7:429-440.

50. Raghu G, Collard HR, Anstrom KJ, et al. Idiopathic pulmonary fibrosis: clinically meaningful primary endpoints in phase 3 clinical trials. Am J Respir Crit Care Med. 2012;185(10):1044-1048.

51. du Bois RM, Nathan SD, Richeldi L, Schwarz MI, Noble PW. Idiopathic pulmonary fibrosis: lung function is a clinically meaningful endpoint for phase III trials. Am J Respir Crit Care Med. 2012;186(8):712-715.

52. Wells AU, Behr J, Costabel U, et al, European IPFCG. Hot of the breath: mortality as a primary end-point in IPF treatment trials: the best is the enemy of the good. Thorax. 2012;67(11):938-940.

53. du Bois RM, Weycker D, Albera C, et al. Ascertainment of individual risk of mortality for patients with idiopathic pulmonary fibrosis. $\mathrm{Am} \mathrm{J}$ Respir Crit Care Med. 2011;184(4):459-466.

54. Taniguchi H, Ebina M, Kondoh Y, et al. Pirfenidone in idiopathic pulmonary fibrosis. Eur Respir J. 2010;35(4):821-829.

55. Collard HR. Idiopathic pulmonary fibrosis and pirfenidone. Eur Respir J. 2010;35(4):728-729.

56. Richeldi L, Brown KK, Costabel U, et al. Efficacy of the tyrosine kinase inhibitor BIBF 1120 in patients with IPF: consistent pattern of primary endpoint results in sensitivity analyses of the TOMORROW trial. Am J Respir Crit Care Med. 2012;185(1 Meeting Abstracts):A3633.

57. Brown KK, Richeldi L, Costabel U, et al. Treatment of IPF with the tyrosine kinase inhibitor BIBF 1120: patient-reported outcomes in the TOMORROW trial. Am Journal of Respiratory and Critical Care Medicine. 2012;185(1 Meeting Abstracts):A3634.

58. Swigris JJ, Brown KK, Behr J, et al. The SF-36 and SGRQ: validity and first look at minimum important differences in IPF. Respir Med. 2010;104(2):296-304

59. Collard HR, Moore BB, Flaherty KR, et al. Acute exacerbations of idiopathic pulmonary fibrosis. Am J Respir Crit Care Med. 2007;176(7): 636-643.

60. Huie TJ, Olson AL, Cosgrove GP, et al. A detailed evaluation of acute respiratory decline in patients with fibrotic lung disease: aetiology and outcomes. Respirology. 2010;15(6):909-917.

61. Azuma A, Nukiwa T, Tsuboi E, et al. Double-blind, placebo-controlled trial of pirfenidone in patients with idiopathic pulmonary fibrosis. Am J Respir Crit Care Med. 2005;171(9):1040-1047.

62. Noble PW, Albera C, Bradford WZ, et al. Pirfenidone in patients with idiopathic pulmonary fibrosis (CAPACITY): two randomised trials. Lancet. 2011;377(9779):1760-1769.

63. Bouche O, Maindrault-Goebel F, Ducreux M, et al. Phase II trial of weekly alternating sequential BIBF 1120 and afatinib for advanced colorectal cancer. Anticancer Res. 2011;31(6):2271-2281.

64. Reck M, Kaiser R, Eschbach C, et al. A phase II double-blind study to investigate efficacy and safety of two doses of the triple angiokinase inhibitor BIBF 1120 in patients with relapsed advanced non-small-cell lung cancer. Ann Oncol. 2011;22(6):1374-1381. 


\section{Publish your work in this journal}

Drug Design, Development and Therapy is an international, peerreviewed open-access journal that spans the spectrum of drug design and development through to clinical applications. Clinical outcomes, patient safety, and programs for the development and effective, safe, and sustained use of medicines are a feature of the journal, which

has also been accepted for indexing on PubMed Central. The manuscript management system is completely online and includes a very quick and fair peer-review system, which is all easy to use. Visit http://www.dovepress.com/testimonials.php to read real quotes from published authors.

Submit your manuscript here: http://www.dovepress.com/drug-design-development-and-therapy-journal 